\title{
INSTITUIÇÕES, DESENVOLVIMENTO E INCLUSÃO
}

Flávio Marques Prol

INSTITUTIONS, DEVELOPMENT AND INCLUSION

RESENHA

ACEMOGLU, DARON E ROBINSON, JAMES. WHY NATIONS FAIL: THE ORIGINS OF POWER, PROSPERITY AND POVERTY. NEW YoRK: CROWN PUBLISHERS. 2012.

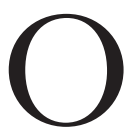
recente livro de Daron Acemoglu e James Robinson, Why nations fail: the origins of power, prosperity and poverty, apresenta o resultado de quinze anos de pesquisa sobre as origens do desenvolvimento. Para os autores, as instituições ocupam papel central nesse processo. As nações bem sucedidas são aquelas que constroem instituições políticas e econômicas "inclusivas", ao contrário das instituições "extrativas”, comuns nas nações que falham. Tentarei explicar e criticar o que autores entendem por esses conceitos ao longo do texto.
Daron Acemoglu é professor de economia no MIT ("Massassuchetts Institute of Technology") e em 2005 ganhou o concorrido prêmio "John Bates Clark Medal", de economistas até 40 anos de idade. James Robinson é professor de ciência política na Universidade de Harvard. Ambos são autores centrais na literatura sobre desenvolvimento, desde o controverso The colonial origins of comparative development (2001), escrito em coautoria com Simon Johnson (também professor no MIT).

Nesse novo texto, os autores optam por debater as grandes questões do desenvolvimento, contra a recente tendência da 
literatura de focar em problemas micro (como em Banerjee e Duflo: 2007 e 2011, por exemplo). A abordagem micro parece ganhar cada vez mais espaço nas discussões sobre desenvolvimento, e no tema próximo de combate a pobreza, uma vez que ela é bastante especializada, setorial e porque permite o aprimoramento imediato de políticas. Contudo, ela não parece apta a resolver importantes problemas que continuam na agenda do tema do desenvolvimento, como o da relação entre democracia e crescimento econômico, por exemplo.

Outra opção dos autores é fugir de explicações deterministas do desenvolvimento, como no caso de hipóteses que dão muita relevância a fatores geográficos na determinação da riqueza nacional (como no livro de Diamond: 1997) ou em explicações culturalistas. A lição que Acemoglu e Robinson retiram das histórias nacionais desenvolvidas em seu livro é a de que são as instituições as responsáveis pelo desenvolvimento, e não qualquer berço de ouro de recursos naturais.

Nessa resenha, inicialmente apresentarei a tese central dos autores, na qual as instituições políticas e econômicas são responsáveis por definir o fracasso ou o sucesso das nações (1). Na sequência, indicarei dois limites metodológicos da abordagem adotada no texto (2). Por fim, tentarei demonstrar como a definição insuficiente de "instituições políticas e econômicas", em especial das inclusivas, resulta em problemas teóricos que podem inviabilizar a tese mais geral dos autores (3).

\section{ENTRE O VÍCIO E A VIRTUDE}

O principal argumento dos autores é o de que uma análise conjunta de instituições políticas e econômicas pode explicar o sucesso ou o fracasso das nações. Ou seja, para um país ser considerado bem sucedido no caminho do desenvolvimento, deve-se observar o desenho de suas instituições. Para compreender como a tese central dos autores é construída ao longo do texto, por meio dos diversos exemplos históricos específicos a determinados países, dois conceitos são fundamentais.

O primeiro é o de "ciclo virtuoso". Acemoglu e Robinson se utilizam principalmente dos exemplos dos Estados Unidos do "New Deal" e da Revolução Gloriosa Inglesa para definir ciclo virtuoso como o surgimento de instituições políticas e econômicas inclusivas que se reforçam reciprocamente. Não há no texto qualquer definição clara e objetiva do que os autores entendem por instituições inclusivas.

Acemoglu e Robinson defendem que as instituições políticas inclusivas resultam de um conflito entre elites e grupos desafiantes oriundos da sociedade civil, o qual enfraquece o poder das primeiras, incentivando a formação de uma sociedade pluralista, na qual ninguém possui poder para estabelecer, sozinho, "as regras do jogo". Essa impossibilidade favorece o compartilhamento do poder político entre os diversos grupos sociais e o ideal de que todas e todos devem ser igualmente respeitados pelo poder político. Nesse contexto, é muito provável a efetivação de um ciclo virtuoso, com a constituição permanente de instituições políticas e econômicas inclusivas. 
As instituições econômicas inclusivas de Acemoglu e Robinson remetem à concepção de economia de mercado, aliada a um argumento schumpeteriano. Para os autores, instituições econômicas inclusivas garantem a propriedade privada e a concorrência, o que encorajaria investimentos em novas tecnologias que possibilitam o crescimento sustentado. $\mathrm{Na}$ visão dos autores, a inovação faz parte do processo da "destruição criadora”, que substitui as técnicas ultrapassadas pelas mais recentes e desestabiliza relações de poder.

O ciclo virtuoso funciona principalmente por meio de três instrumentos: (i) devido à lógica pluralista da sociedade política emergente, dificulta-se a tomada do poder político por um ditador ou grupo, além de se fortalecer a noção de que a lei deve ser aplicada de forma igual a todas e todos (rule of law), o que induz à crescente participação e inclusão políticas; (ii) instituições políticas inclusivas fortalecem instituições econômicas inclusivas $e$ vice-versa, o que prejudica a existência de relações econômicas extrativas, como servidão e escravidão; (iii) instituições políticas inclusivas permitem o surgimento de uma mídia independente, que fornece informações e mobiliza oposição a ameaças a elas.

O segundo conceito central do livro é o de "ciclo vicioso". Segundo os autores, um ciclo vicioso pode ser definido como a persistência de instituições políticas e econômicas extrativas que, embora não sejam inquebrantáveis, têm uma resistência significativa. No ciclo vicioso, instituições políticas e econômicas também se reforçam mutuamente. Acemoglu e Robinson não apresentam uma definição clara do que entendem por instituições extrativas, mas definem suas duas configurações mais comuns.

A primeira é a do domínio contínuo das elites, que estruturam instituições extrativas que as enriquecem e permitem a perpetuação da dominação. Um exemplo apresentado é a trajetória de Serra Leoa: após a formação de instituições extrativas para extração de diamantes pelos colonizadores britânicos, por meio do monopólio da exploração, do controle do comércio externo e do governo indireto por chefes de tribos regionais, não houve incentivos para alterações substantivas, mesmo com a independência nacional. A elite que permaneceu no poder foi a mesma. Na visão dos autores, isso levou a longos períodos de governo despótico, simbolizado pelo regime de Siaka Stevens.

A segunda expressão do ciclo vicioso é a da "lei de ferro da oligarquia", terminologia adotada a partir do trabalho de Robert Michels. A ideia é a de que, em sistemas oligárquicos, as elites podem até mesmo variar, mas as instituições extrativas permanecem. Isso decorreria das poucas restrições ao exercício do poder quando da existência de instituições extrativas, o que incentivaria a sua perpetuação por outros grupos desafiantes, ao invés do surgimento de uma sociedade pluralista.

O exemplo ilustrativo da lei de ferro da oligarquia é o a da Etiópia. A derrota da dinastia salomônica em 1974 por um movimento militar liderado por marxistas, 
após séculos de exploração e governo despótico, não produziu democracia ou desenvolvimento para o país. Para os autores, ocorreu justamente o contrário: o grupo marxista liderado por Mengistu simplesmente se apoderou das mesmas instituições extrativas já existentes, em especial do monopólio para extração de recursos naturais e do controle direto e indireto sobre a produção agrícola, para se fortalecer no poder.

A questão que surge a partir dessas definições diz respeito ao modo como ocorre a transição do ciclo vicioso para o virtuoso. Acemoglu e Robinson defendem que um dos fatores chave para a transformação é a formação de ampla coalizão de atores e interesses, que permite a emergência de instituições políticas pluralistas. O exemplo é o da Revolução Gloriosa Inglesa, na qual à derrocada do absolutismo não se seguiu a formação de um poder social capaz de dominar sozinho o poder político. A partir de outros exemplos históricos, os autores incluem a existência de elementos inclusivos nas próprias instituições locais extrativas e a "natureza contingente da história" como mais dois elementos do movimento rumo a instituições inclusivas e um ciclo virtuoso.

\section{A CONTINGÊNCIA HISTÓRICA E A} NAÇÃO COMO UNIDADE DE ANÁLISE Após essa apresentação da principal hipótese do livro de Acemoglu e Robinson, é possível esboçar duas críticas metodológicas ao trabalho: (i) o modo como a ideia de contingência histórica é incorporada para escapar de conclusões deterministas; (ii) a escolha da nação como unidade de análise, que ignora outras influências na trajetória do desenvolvimento de um país.

Como já foi possível perceber, os autores se utilizam fartamente da história para ilustrar como suas hipóteses fazem sentido. Porém, Acemoglu e Robinson não parecem permitir que histórias específicas modifiquem suas formulações. Isso fica claro se pensarmos que nas mais de 500 páginas (e nas dezenas de exemplos fornecidos), não há qualquer narrativa distinta do modelo ciclo virtuoso/vicioso apresentado acima. Nesse sentido, podese defender que eles fazem uma leitura estilizada da história, de modo a tão somente confirmar suas hipóteses.

Por outro lado, o livro parece incorporar a ideia de contingência para evitar que uma crítica a partir dessa atitude dos autores frente aos dados históricos não pareça suficientemente forte. Nesse sentido, é fundamental ter reservas com conclusões precipitadas, uma vez que admitem que o poder de predição de sua teoria é limitado. Para eles, pequenas diferenças e a contingência são integrantes do próprio desenvolvimento histórico, não somente da teoria - o que, aliás, é extremamente plausível. Detalhes provocam alterações significativas no caminho do desenvolvimento.

Assim, os autores incorporam o conceito de contingência em suas análises, evitando críticas que apontem, por exemplo, que determinado país construiu instituições políticas inclusivas, mas a partir das quais não se seguiu um ciclo virtuoso. Acemoglu e Robinson blindam-se 
ao definirem o rumo da história como incerto. Portanto, embora seja possível apontar a ausência de países fundamentais no texto, como Alemanha e Itália no início do século $\mathrm{XX}$, isso não me parece ser uma crítica que atinja os fundamentos da hipótese central dos autores, ainda que seja válida.

Os casos da Alemanha e da Itália são especialmente importantes porque resultaram nas experiências do nazismo e do fascismo. Seria igualmente importante se dedicar a pesquisar como instituições ditas inclusivas (no caso alemão, em especial) puderam dar origem a instituições radicalmente excludentes (o clássico Behemoth, de Neumann: 2009, poderia ajudar nesse sentido). Da mesma forma, caberia questionar se os modelos da Alemanha e da Itália "falharam" por razões internas ou acabaram fracassando somente porque foram derrotados na guerra.

Um segundo e mais grave problema metodológico decorre da escolha da nação como unidade de análise, excluindo as relações entre elas, tanto da perspectiva política quanto da perspectiva econômica. Assim, Acemoglu e Robinson ignoram efeitos políticos e econômicos negativos que essas relações podem gerar. É sintomático, por exemplo, que os autores citem como virtuosa a Inglaterra, a qual, segundo eles próprios, impôs instituições extrativas a suas colônias, como Serra Leoa.

Ou seja, os autores desconsideram o impacto das relações internacionais na determinação das instituições políticas e econômicas de cada nação. Nesse sentido, não incorporam contribuições centrais para o estudo do desenvolvimento, como a literatura sobre dependência, na qual as relações entre nações ganham proeminência, sem que fatores endógenos sejam ignorados.

\section{O QUE SÃo INSTITUIÇÕES INCLUSIVAS?}

Para além das questões metodológicas, duas objeções fundamentais podem ser apresentadas ao texto: (i) instituições políticas inclusivas não fomentam instituições econômicas inclusivas; (ii) a formulação do que são instituições políticas e econômicas inclusivas é fraca ou insuficiente no texto. ${ }^{1}$

A primeira hipótese, que não abordarei aqui, teria que reapresentar o desenvolvimento histórico dos países estudados no livro de modo a demonstrar o conflito das instituições políticas e econômicas inclusivas, ao invés de seu reforço mútuo. Isso parece ser feito, por exemplo, em texto recente de Wolfgang Streeck (2012). Nele, embora não dialogando diretamente com o argumento de Acemoglu e Robinson, Streeck apresenta a hipótese de que o capitalismo democrático é uma conformação instável, uma vez que as instituições democráticas tendem a exigir das instituições econômicas arranjos imperfeitos do ponto de vista da eficácia do livre mercado. Ou seja, a democracia gera problemas para a economia de mercado funcionar adequadamente.

A segunda objeção, que trabalha com a ideia de formulação insuficiente do significado de instituições políticas e econômicas inclusivas no texto, interessa-me 
mais. A partir dela, é possível desenvolver com maiores detalhes alguns argumentos. Em primeiro lugar, as palavras "virtuoso" e "vicioso" já trazem em si avaliação normativa sobre as instituições de um ciclo e de outro. Assim, dada a diferença entre o que é ruim (vicioso) e o que é bom (virtuoso), seria adequado identificar claramente o que caracteriza cada um dos ciclos. Ou seja, o que define as instituições inclusivas, para os autores?

No texto, as instituições políticas inclusivas são: sociedade pluralista, rule of law, democracia e mídia independente, que surgem do conflito entre elites e cidadãos. As instituições econômicas inclusivas, por outro lado, são: concorrência, propriedade privada e garantia dos contratos, que permitem a "destruição criadora", a qual favorece a inovação e o empreendedorismo. As formas de uma nação construir essas instituições variam amplamente, como admitem os próprios autores. Nesse sentido, seria essencial esclarecer: na definição de ciclo virtuoso, há um ideal de democracia, no qual as diferenças entre elites e cidadãos não existem mais, tanto da perspectiva das instituições econômicas como políticas, já que as instituições inclusivas surgem justamente do conflito entre eles? Ou ainda: há limite da inclusão dos cidadãos nas instituições, a partir do qual se obstaculiza o desenvolvimento?

Acemoglu e Robinson provavelmente responderiam afirmando que sua teoria não está interessada em apresentar todas as variáveis que determinam o sucesso ou fracasso de uma nação, mas somente um panorama geral suficientemente coerente e plausível para explicar porque algumas falharam, enquanto outras foram bem sucedidas. Mesmo assim seria necessário definir o que é uma nação bem sucedida. A pergunta sobre como definir sociedades virtuosas continua essencial porque, se mesmo aquelas que os autores definiram como virtuosas não puderem ser consideradas bem sucedidas, a divisão entre ciclos virtuosos e viciosos fica pelo menos em xeque.

Para esboçar uma possível resposta, é curioso notar o conservadorismo dos autores quando elogiam a Revolução Gloriosa em comparação à Revolução Francesa: "Há uma grande virtude nesse tipo de mudança gradual. É menos ameaçadora à elite que a total derrocada do sistema. Cada etapa é pequena, e faz mais sentido ceder a uma pequena demanda do que criar uma grande confrontação" (ACEMOGLU e ROBINSON: 2012, 317). ${ }^{2}$ A partir dessa passagem, é possível afirmar que os autores defendem as instituições políticas inclusivas porque elas garantem a manutenção do sistema com crescimento econômico, mas não porque são inclusivas. Só assim seria possível compreender sua preferência pelas mudanças graduais.

Ou seja, o que importa para a definição do ciclo virtuoso não é a possibilidade de inclusão por meio das instituições, mas o contínuo funcionamento da sociedade capitalista com crescimento econômico. Se isso é o que define o sucesso ou o fracasso das nações, Acemoglu e Robinson deveriam modificar sua hipótese central para afirmar: não há sucesso ou fracasso das nações com base na análise das instituições inclusivas, mas sim dos resultados econômicos e da estabilidade política. 
Em outras palavras, por essa passagem e pela falta de definição clara sobre o que são instituições inclusivas, é impossível avaliar se determinado arranjo institucional é melhor que outro por si só. Ele será melhor se trouxer melhores resultados econômicos e ordem política. Portanto, a característica inclusiva das instituições é instrumental em relação aos resultados econômicos e de estabilidade política (a estabilidade por si só também é garantida no ciclo vicioso).

Inclusive é possível que determinado grau de inclusão política - mais substantiva do que a realização de eleições formais e periódicas e da garantia do rule of lawnão seja suportado pelas instituições econômicas que garantem o crescimento econômico. Essa conclusão impede a própria hipótese mais geral sobre o ciclo virtuoso e explicaria a preferência dos autores por mudanças graduais.

Em trabalhos anteriores, os autores eram menos ambiciosos e mais explícitos. A expressão "instituições inclusivas” não era utilizada e a democracia era definida claramente de modo formal e restrito: no texto de 2001, citado na introdução, os autores afirmam "há um 'grupo (cluster) de instituições', incluindo restrições à capacidade de expropriação pelo governo, judiciário independente, garantia dos direitos de propriedade e instituições que providenciem acesso igual à educação e que assegurem liberdades civis, que é importante para encorajar o investimento e o crescimento" (pp. 1371-1372). ${ }^{3}$ Não se trata de afirmar que essas instituições não sejam importantes. Mas a defesa delas não deveria ser feita somente com base em suas consequências para o crescimento.

Vale ressaltar: a explicação deles do surgimento das instituições inclusivas depende da disputa entre elites e cidadãos. Logo, faria sentido que o parâmetro da inclusão fosse, no limite, o término das diferenças entre os dois grupos. Inclusivo, então, significaria a inclusão igualitária das massas no jogo político. O ponto, entretanto, é saber qual a hipótese do texto: eles definem instituições inclusivas como aquelas que buscam a inclusão efetiva ou querem incluí-las somente até a garantia da ordem e do crescimento econômico? Se o posicionamento deles for mais próximo da primeira alternativa, é difícil conciliá-la com seu posicionamento sobre as Revoluções Francesa e Gloriosa.

Uma definição sobre o que caracteriza a inclusão das instituições também permitiria distinguir quais são as nações que podem ser classificadas como virtuosas, sem ficar nos exemplos extremos dos Estados Unidos e da Inglaterra vis a vis os países mais pobres do mundo. Mas, para isso, seria necessário um esforço teórico de lidar com a extensa literatura sobre a importância intrínseca da democracia e como ela possibilita demandas por reconhecimento e inclusão, o que diversas vezes afeta o funcionamento da economia de mercado. Entretanto, esse debate é deixado de lado pelo texto.

Em resumo, ao não teorizarem suficientemente sobre sua posição a respeito das instituições inclusivas que determinam o sucesso de um ciclo virtuoso, os autores acabam adotando uma perspectiva conservadora - "a inclusão deve ocorrer 
gradualmente”- e instrumental - “a inclusão é importante para garantir o crescimento econômico e a ordem" - que pode, no limite, inviabilizar a própria hipótese da qual os autores partiram, a de que o critério adequado para mensurar o surgimento de um ciclo virtuoso são as instituições inclusivas.

De todo modo, o livro tem o mérito de apresentar uma pesquisa extensa e abrangente que coloca a política e o desenho das instituições como o núcleo da explicação do sucesso ou do fracasso das nações, em detrimento de posições deterministas. No contexto internacional, a hipótese não deixa de ser curiosa: ela foi apresentada em plena crise europeia, na qual crises econômicas e políticas ocorrem justamente em países considerados virtuosos, com conflitos entre as instituições políticas inclusivas e as instituições econômicas.
1 Acredito que o mesmo raciocínio possa ser feito em relação à definição de instituições políticas e econômicas extrativas. Contudo, para simplificar o argumento, trabalharei somente com a definição das instituições inclusivas.

2 Tradução livre. A passagem no original é a seguinte: "There is great virtue in this sort of gradual change. It is less threatening to the elite than the wholesale overthrow of the system. Each step is small, and it makes sense to give in to a small demand than create a major showdown."

3 Tradução livre. A passagem, no original, é a seguinte: "Our view is that there is a 'cluster of institutions', including constraints on government expropriation, independent judiciary, property rights enforcement, and institutions providing equal access to education and ensuring civil liberties, that are important to encourage investment and growth.”

\section{REFERÊNCIAS BIBLIOGRÁFICAS}

ACEMOGLU, D. e ROBINSON, J. (2012). Why nations fail: the origins of power, prosperity and poverty. New York: Crown Publishers. Para outras informações, ver também o site oficial do livro: http://whynationsfail.com/
ACEMOGLU, D., JOHNSON, S. e ROBINSON, J. (2001). The American Economic Review. Vol. 91, No. 5, pp. 1369-1401. BANERJEE, A. e DUFLO, E. (2007). "The economics lives of the poor", Journal of Economic 
Perspectives. Vol. 21, 1: 141-167.

BANERJEE, A. e DUflO, E. (2011). Poor

economics: a radical rethinking of the way to fight global poverty. New York: Public Affairs.

DIAMOND, J. (1997). Guns, germs and steel: the fates of

human societies. New York: W. W. Norton \& Company.
NEUMANN, F. (2009). Behemoth: the structure and practice of national socialism, 1933-1944. Chicago: Ivan R. Dee.

STREECK, W. (2012). “As crises do capitalismo democrático", in Novos Estudos Cebrap, 92, Abril de 2012.
Rua Egydio Martins, n. 85, ap. 82 Ponta da Praia - 11030-16 Santos - SP - Brasil flavio.prollausp.br
Flávio Marques Prol

Mestrando pelo Departamento de Filosofia e Teoria Geral do Direito da Faculdade de Direito da Universidade de São Paulo Pesquisador do Núcleo de Direito e Democracia do Centro Brasileiro de Análise e Planejamento (CEBrap) 
